\title{
Clinical Dopplerographic Correlates of a Continuous Long-Term Ethy imethy thydroxypyridine Succinate Infusion in Acute Concomitant Traumatic Brain Injury
}

\author{
DOI: $10,17691 / \mathrm{stm} 2016.8 .4 .12$
}

Received June 19, 2016

E.A. Abramova, Anesthesiologist, Resuscitator, Resuscitation and Intensive Care Unit,

Nizhny Novgorod Regional Traumatology Center';

A.0. Trofimov, MD, PhD, Assistant, Department of Neurology, Neurosurgery and Medical Genetics²;

G.A. Boyarinov, MD, DSc, Professor, Head of the Department of Anesthesiology and Resuscitation,

Faculty of Doctors' Advanced Training';

O.V. Voennov, MD, DSc, Professor, Department of Anesthesiology and Resuscitation,

Faculty of Doctors' Advanced Training ${ }^{2}$

Nizhny Novgorod Regional Clinical Hospital named after N.A. Semashko, 190 Rodionova St.,

Nizhny Novgorod, 603126, Russian Federation;

${ }^{2}$ Nizhny Novgorod State Medical Academy, 10/1 Minin and Pozharsky Square, Nizhny Novgorod, 603005,

Russian Federation

The aim of the investigation was to assess the efficiency of a long-term ethylmethylhydroxypyridine succinate (EMHPS) infusion in patients with severe concomitant traumatic brain injury (TBI) by the dynamics of cerebral macrocirculation, consciousness level and state severity index.

Materials and Methods. We examined two groups of patients, 25 patients in each group, with severe concomitant TBI. The $1^{\text {st }}$ group (control) patients underwent standard intensive therapy. The $2^{\text {nd }}$ group patients, in addition to standard treatment, had EMHPS infusion in a dose $100 \mathrm{mg} / \mathrm{h}$ through an infusion pump for 10 days. Using transcranial dopplerography we studied linear blood flow rate (LBFR): systolic blood velocity, diastolic blood velocity, mean blood velocity, pulsation index and resistance index, and assessed the consciousness level dynamics using Glasgow coma scale and the severity of patients' state according to APACHE II.

Results. In the $1^{\text {st }}$ group patients LBFR normalized in $24,32,48$ and $72 \%$ cases on day 3,57 and 10 , respectively, while in the $2^{\text {nd }}$ group patients, LBFR values normalized in $48,60,64$ and $80 \%$ cases within the same period. When using EMHPS, the quicker consciousness recovery was reported: in 60 and $24 \%$ patients, respectively, in groups 2 and 1 by day 5 ; in 80 and $60 \%$ patients by day 10 . In the $2^{\text {nd }}$ group patients by day 10 the severity index values according to APACHE II were 2 times less than in group 1.

Conclusion. Long-term (within 10 days) EMHPS infusion in a dose of $100 \mathrm{mg} / \mathrm{h}$ in patients with severe TBI contributes to more rapid normalization of LBFR parameters, consciousness recovery and the decrease of severity according to APACHE II.

Key words: traumatic brain injury; ethylmethylhydroxypyridine succinate; cerebral blood flow; consciousness level; APACHE II.

The application of therapeutic technologies aimed to recover the sufferers with traumatic brain injury (TBI) from shock and homeostasis is an integral part of standard intensive therapy: respiratory support; circulatory support; correction of hemostasis, arterial oxygen content, hydro-electrolytic balance and acid-base balance, metabolism; anaesthesia and sedation; antibacterial therapy; prevention of stress ulcers and thromboembolic complications; enteral and parenteral nutrition; intracranial pressure correction [1-4]. However, mortality indices remain stably high in these patients that stimulates a search for new treatment techniques [5, 6].

One of them can be the application of antihypoxic and antioxidant agents to minimize the development of secondary ischemic brain injury. If blood flow is normalized in the area of "ischemic penumbra", cerebral metabolism and brain functions restore. Moreover, antihypoxic and antioxidant effects, as a rule, are not organ-specific, and have a positive effect on both: neurons, as well as cardiomyocytes, cells of the liver, kidneys, intestine, lungs [7-9].

One of medicinal agents with a proved universal cytoprotective effect including that on the brain is ethylmethylhydroxypyridine succinate (EMHPS) [10-12]. However, no administration results of EMHPS in the form of long-term continuous infusions have been shown in literature.

The aim of the investigation was to assess the efficiency of a long-term ethylmethylhydroxypyridine succinate infusion in patients with severe concomitant

For contact: Oleg V. Voennov, e-mail: ovoennov@yandex.ru 
traumatic brain injury by the dynamics of clinical dopplerograhic indices: linear blood flow rate, consciousness level and state severity index.

\section{Materials and Methods}

Patient population formation. The study involved 50 patients with severe concomitant TBI and injuries of long bones, chest, abdomen; aged 21-60 years, mean age 41.5 [29; 51] years. Among them there were 19 females and 31 males. All patients were admitted to the inpatient department and resuscitation and intensive care unit (RICU) of Nizhny Novgorod Regional Traumatology Center immediately from an accident site or transferred from central district hospitals of Nizhny Novgorod region. Their trauma age did not exceed 3 days. On admission the patients underwent examination according to standards and were administered standard intensive care to stabilize their condition. When patients recovered from traumatic or hemorrhagic shock considering the exclusion and inclusion criteria, the patients were divided into two groups, 25 patients in each group.

The study inclusion criteria were the following: age from 21 to 60 years; moderate and severe TBI associated with extracranial injuries of long bones and/ or chest and/or abdomen (consciousness depression is 4-13 points according to Glasgow coma scale - GCS); required treatment in an intensive care unit; consent to EMHPS administration of a patient and/or his legal representatives.

The exclusion criteria were the following: terminal condition (under 4 GCS points); simultaneous administration of other neurotropic agents, which have an effect on cerebral vascular tone; diabetes mellitus; intolerance to EMHPS; requirement for neurosurgical emergency.

Among the first (control) group patients, on admission, the condition of 18 patients was considered as severe, and in 7 patients - very severe. Among the second (study) group patients, 19 patients had severe injury, and 6 - very severe. The patients in a very severe condition had the signs of traumatic or hemorrhagic shock, impaired consciousness, required artificial lung ventilation. On admission the patients of both groups were comparable by age, sex, severity (Table 1).

The study complies with the declaration of Helsinki (adopted in June, 1964 (Helsinki, Finland) and revised in October, 2000 (Edinburg, Scotland)) and was approved by the Ethics Committee of Nizhny Novgorod State Medical Academy. All patients gave their written informed consent.

The first group patients underwent standard treatment including anesthesia and sedation; respiratory support if indicated; antibacterial therapy; infusion-transfusion therapy in order to correct water electrolytic balance blood oxygen capacity, oncotic pressure and disseminated intravascular coagulation prevention; enteral and parenteral feeding; stress-ulcer prevention; intracranial hypertension.

In addition to standard therapy, group 2 patients underwent EMHPS infusion (Mexicor) at a dose of $100 \mathrm{mg}$ per hour through an infusion pump within 10 days. As a single step (on days 3, 5, 7 and 10) against the background of the drug infusion, we studied the patients' condition dynamics: neurological status, consciousness level according to GCS, brain blood flow by transcranial dopplerography, severity by APACHE II. Subsequently, we assessed the treatment outcomes, the length of RICU and hospital stay.

Transcranial dopplegography procedure. The study was performed using an ultrasonic imaging system Sonomed 300B (Spectromed, Russia) by a $2 \mathrm{MHz}$ sensor. We applied a standard technique by Aaslid et al. [13] to probe medial cerebral arteries and other vessels of circle of Willis through the temporal acoustic window. To make the picture of cerebral hemodynamic changes complete, we carried out a complex analysis of linear velocity of blood flow (LVBF) in medial cerebral and basilar arteries. We studied systolic blood velocity (Vmax), diastolic blood velocity (Vmin), mean blood velocity $(\mathrm{Vm})$, pulsation index $(\mathrm{Pl})$ and resistance index (RI). When analyzing LVBF data, the following indices were considered as the norm: Vmax - 80-100 cm/s; Vm - 50-60 cm/s; Vmin $30-50 \mathrm{~cm} / \mathrm{s} ; \mathrm{PI}-0.7-1.0 ; \mathrm{RI}-0.5$ [14].

The findings were statistically processed using a Biostat program, after testing the hypothesis for normality we used the distribution in samplings according to standard formula $[15,16]$. Mean values were represented as $\mathrm{Me}[25 ; 75]$. Statistical significance was defined by Wilcoxon-Mann-Whitney test, the difference being considered significant if $p \leqslant 0.05$.

Table 1

Characteristics of patients in groups (abs. number)

\begin{tabular}{|c|c|c|}
\hline Parameters & Group $1(n=25)$ & Group $2(n=25)$ \\
\hline Males & 15 & 16 \\
\hline Females & 10 & 9 \\
\hline \multicolumn{3}{|c|}{ State: } \\
\hline severe & 18 & 19 \\
\hline very severe & 7 & 6 \\
\hline |solated TBI & 5 & 5 \\
\hline $\begin{array}{l}\text { Concomitant TBI: } \\
\text { with skeletal trauma only } \\
\text { with skeletal trauma and injuries }\end{array}$ & 3 & 2 \\
\hline of thoracic organs and/or abdomen & 17 & 18 \\
\hline \multicolumn{3}{|l|}{$\begin{array}{l}\text { Consciousness level according to GCS } \\
\text { (points): }\end{array}$} \\
\hline $11-13$ & 14 & 15 \\
\hline $8-10$ & 8 & 8 \\
\hline 4-7 & 3 & 2 \\
\hline $\begin{array}{l}\text { State severity according to APACHE II } \\
\text { (Me }[25 ; 75] \text { ) }\end{array}$ & $22[18 ; 24]$ & $23[19 ; 25]$ \\
\hline
\end{tabular}


Results. When carrying out a dopplerographic test of brain circulation, pathological divergence of dopplerogram parameters (LVBF disturbance) was found in all patients in both groups. Hindered perfusion was revealed in 60 and $64 \%$ cases in groups 1 and 2, respectively. Angiospasm pattern ranked the second to be recorded: 24 and $20 \%$, respectively. 2 patients in each group were found to have hypoperfusion pattern, as well as 2 cases in each group appeared to have hyperperfusion. The regression changes of linear blood indices showed the following: in the first group patients, the data normalization was found on day 3 in $24 \%$ cases, on day $5-$ in $32 \%$, on day $7-$ in $48 \%$, on day $10-$ in $72 \%$, while in the second group cerebral blood flow normalized on day 3 in $48 \%$ cases, on day $5-$ in $60 \%$, on day $7-$ in $64 \%$, on day $10-$ in $80 \%$ cases (Figure 1).

Therefore, a long (10 days) EMHPS infusion at the dose of $100 \mathrm{mg} / \mathrm{h}$ in patients with TBI contributes to faster normalization of the cerebral blood flow parameters.

The analysis of consciousness level dynamics by GCS in group 2 showed a favorable course of a posttraumatic acute period in 20 patients $(80 \%)$ (Table 2 ). By day 5 the consciousness recovered up to 15 points according to GCS in all patients with the depression of consciousness $11-13$ points (15 patients, or $60 \%$ of patients of the group) admitted to RICU. By day 10 of the treatment, the consciousness recovered to clear consciousness in

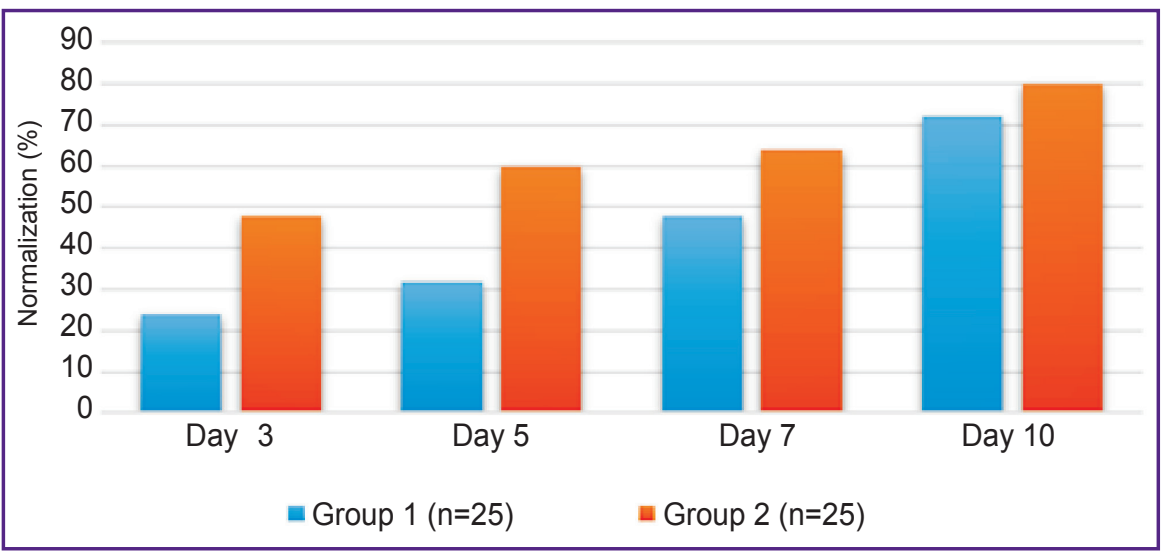

Figure 1. Normalization of linear blood flow indices in patients with traumatic brain injury after a long EMHPS infusion at different study stages

Table 2

Recovery of consciousness in patients with traumatic brain injury; Glasgow Coma Scale (points)

\begin{tabular}{lccccc}
\hline \multicolumn{1}{c}{ Study stages } & \multicolumn{2}{c}{ Group 1 $(\mathrm{n}=25)$} & \multicolumn{2}{c}{ Group 1 $(\mathrm{n}=25)$} \\
\cline { 2 - 5 } & abs. number & $\%$ & abs. number & $\%$ \\
\hline Day 5 (complete consciousness recovery) & 6 & 24 & 15 & 60 \\
\hline Day 10 (complete consciousness recovery) & 15 & 60 & 20 & 80 \\
\hline Day 10 (consciousness level 11-13 points) & 7 & 28 & 3 & 12 \\
\hline Day 10 (consciousness level 8-10 points) & $\begin{array}{c}1 \text { (2 lethal } \\
\text { outcomes) }\end{array}$ & $\begin{array}{c}4 \\
(8 \%)\end{array}$ & 2 & 8 \\
\hline
\end{tabular}

other 5 patients with the depression of consciousness 8-10 points admitted to ICU.

Thus, by day 10 of the investigation, clear consciousness recovered in 20 patients (in $80 \%$ cases). By the end of the study, the impaired consciousness persisted in 5 patients only. Three patients among them with initial level of consciousness $8-10$ points had the increase in consciousness level up to 11-13 points by day 10 followed by complete clear consciousness recovery and discharge from the hospital, and in 2 patients with initial depression of consciousness being 5 and 7 points, by day 10 were found to have their consciousness level increased up to 9 and 10 points, respectively. Later on, after a long therapy period (43 and 38 days) in RICU, the patients were discharged from hospital, their consciousness level being 13 and 14 points.

In group 1 by day 5 of treatment the consciousness recovered only in 6 patients, and by day 10 - in 15 patients ( $60 \%$ patients of the group). In 7 of 8 patients with an initial consciousness level 8-10 points were found no complete recovery of consciousness, their depression level ranged from 11 to 13 points. One of 3 patients admitted with the depression of consciousness 4, 5 and 7 points, was observed to have a consciousness level increase up to 10 points by day 10 . Other two patients died on day 3 and 9 of the investigation against the background of progressive cerebral edema (lethality is $8 \%$ ) (See Table 2).

Therefore, a long (10 days) EMHPS infusion at a dose of $100 \mathrm{mg} / \mathrm{h}$ in TBI patients was found to contribute to more rapid and complete consciousness recovery in most patients.

When estimating the severity we revealed the following. When including the patients into the study, the severity according to APACHE II was from 16 to 28 points, the risk of death being from 23.5 to $63.9 \%$. Further, all survived patients had the regress of severity and death risk. By day 10 the severity in most patients was from 7 to 11 points, the death risk being $7.6-12.9 \%$.

The first group patients were found to have the decrease of state severity index according to APACHE II up to the level of under 7 points in 4 patients $(17.4 \%$ of survived patients), and up to the level from 7 to 11 points - in 12 patients $(52.2 \%)$, over 11 points in 7 patients $(30.4 \%)$ (Table 3$)$. The state severity index according 
Table 3

Severity dynamics in patients with traumatic brain injury (according to APACHE II) by day 10

\begin{tabular}{lcccc}
\hline $\begin{array}{l}\text { Severity index according } \\
\text { to APACHE II }\end{array}$ & \multicolumn{2}{c}{ Group 1 $(\mathrm{n}=25)$} & \multicolumn{2}{c|}{ Group 1 (n=25) } \\
\cline { 2 - 5 } & abs. number & $\%$ & abs. number & $\%$ \\
\hline Less than 7 points & 4 & 17.4 & 9 & 36 \\
\hline 7-11 points & 12 & 52.2 & 14 & 56 \\
\hline Over 11 points & 7 & 30.4 & 2 & 8 \\
\hline
\end{tabular}

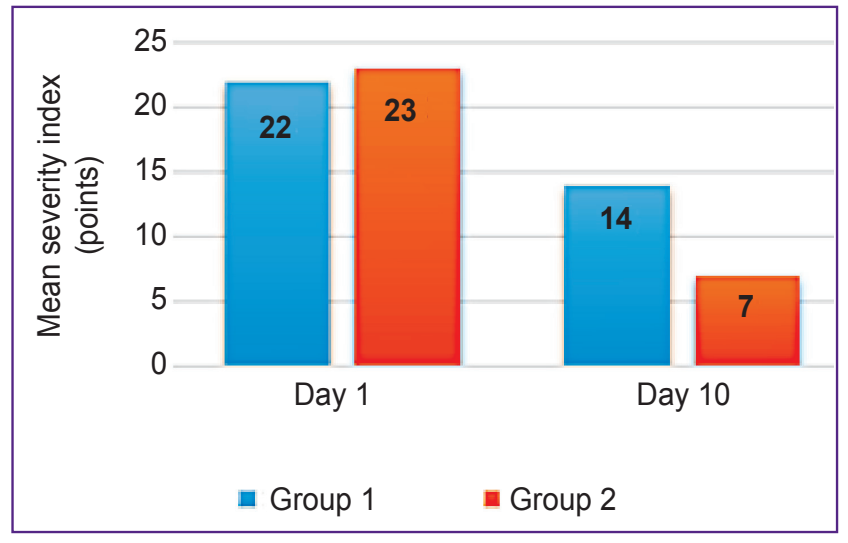

Figure 2. Dynamics of severity index according to APACHE II in patients with traumatic brain injury after a long EMHPS infusion

to APACHE II decreased by day 10 from 22 [18; 24] to 14 $[11 ; 16]$ points, i.e. by 1.5 times (Figure 2 ).

In the second group there was the decrease in severity index according to APACHE II up to the level of under 7 points in 9 patients (36\% of survived patients), up to the level from 7 to 11 points - in 14 patients (56\%), over 11 points - in 2 patients (8\%) (See Table 3). The severity index according to APACHE II scale by day 10 decreased from $23[19 ; 25]$ to $7[5 ; 10]$ points, i.e. by 3.1 times (See Figure 2). Two patients with the severity index 15 and 23 points were the exception, their index decreasing on average only by 1.35 times.

Thus, a long (10 days) EMHPS infusion at a dose of $100 \mathrm{mg} / \mathrm{h}$ in TBI patients contributes to more rapid normalization of cerebral flow parameters, state recovery and severity index reduction in most patients.

Discussion. The most common patterns found in the examined patients with TBI were hindered perfusion and angiospasm. Hindered perfusion pattern is associated with cerebral edema development and increased intracranial pressure resulting in a slow cerebral blood flow, to a greater degree, in the diastole phase due to blood stream compression. Angiospasm pattern serves as a sign of traumatic subarachnoid hemorrhage causing arteriolar spasm. Hypoperfusion pattern is due to low systemic arterial pressure and occur in patients with arterial hypotension. Hyperperfusion pattern was recorded in patents when hypoperfusion, angiospasm or hindered perfusion was eliminated. Cerebral perfusion (LVBF indices) causes the consciousness depression level and influences the severity of the patients' condition. The more marked cerebral edema, angiospasm and ischemia, the more expressed the depression of consciousness and the worse severity index according to APACHE II.

In acute TBI some patterns transform into others. All survived patients in both groups had pathological patterns of cerebral blood flow, which transformed through a stage of reactive hyperemia to normal macrocirculation values that preceded the cerebral function normalization. Thus, hyperperfusion pattern is the manifestation of sanogenesis regardless an initial pathological pattern (hypoperfusion, hindered perfusion, angiospasm). It is consistent with the general notion of the importance of cerebral perfusion pressure for prognosis in TBI patients.

In 2 group patients, in the half of cases, LVBF normalized as early as by day 3 of the treatment, while in the patients of group $1-$ only by day 7 . Therefore, continuous EMHPS infusion enables to normalize cerebral blood flow more rapidly in most patients regardless of an initial pattern. The mechanism of this effect is most likely related to a vasomodulating effect of EMHPS on a vascular wall that makes it possible either to eliminate excess vascular tone in angiospasm, or increase a low tone in hypoperfusion and hindered perfusion. Moreover, a positive inotropic effect of EMHPS is likely to be of importance. As a whole, all this together with a cytoprotective substrate effect of EMHPS results in the improved ischemic area condition.

Cerebral blood flow improvement (according to transcranial dopplerography findings) results in the recovery and improvement of consciousness level (according to GCS), and especially in patients with initial sopor-stupor that is explained by normalization of perfusion-metabolic interactions under EMHPS. In patients admitted in coma, a positive effect of EMHPS is not so convincing and expressed; however, the result is better than in the control group. In turn, an increased level of consciousness, wakefulness, physical activity, recovering of upper airway reflexes is the manifestation of a regress of cerebral dysfunction, and accompanied by the decrease of severity index (according to severity scale APACHE II). It could be promoted by a universal cytoprotective effect of EMHPS on other organs and systems. In addition, the fact that EMHPS infusion was continuous, long, at therapeutical doses was of great significance as well that provided a curative effect not occasionally, but continuously, within 10 days.

Conclusion. A long EMHPS infusion at a dose of $100 \mathrm{mg} / \mathrm{h}$ in patients with traumatic brain injury contributes to more rapid normalization of the linear velocity of cerebral flow, consciousness recovery and downward change in state severity index.

Study Funding and Conflicts of Interest. The study was not funded by any sources, and the authors have no conflicts of interest related to the present study. 


\section{References}

1. Potapov A.A., Konovalov A.N., Korniyenko V.N., Kravchuk A.D., Likhterman L.B., Pronin I.N., Zakharova N.Ye., Gavrilov A.G., Okhlopkov V.A., Yeolchiyan S.A., Zaytsev O.S., Yakovlev S.B., Gorkov K.M., Oshorov A.V., Shurkhay V.A The target scientific and technical program - strategic way of solution of social and medical problems related to craniocerebral trauma. Rossiyskie meditsinskie vesti 2010; 15(3): 92-96.

2. Langlois J.A., Rutland-Brown W., Wald M.M. The epidemiology and impact of traumatic brain injury: a brief owerwiew. J Head Trauma Rehabil 2006; 21(5): 375-378, https://doi.org/10.1097/00001199-200609000-00001.

3. Midori I.M., Bersnev V.P., Ryabukha N.P. Syndrome of brain compression in cranio-cerebral trauma. Vestnik khirurgii im. I.I. Grekova 2012; 171(6): 66-68.

4. Moroz V.V., Karmen N.B., Mayevsky E.I. Mechanisms of secondary neuronal damage in severe brain injury (part 2). Obshchaya reanimatologiya 2011; 7(5): 44-47.

5. Shmakov A.N., Danchenko S.V. The study of "a golden hour" in severe traumatic brain injury. Meditsinskiy alfavit 2011; 1(3): 38-40.

6. Talypov A.E., Petrikov S.S., Puras Yu.V., Solodov A.A., Titova Yu.V. Current treatments for brain contusions. Nevrologiya, neyropsikhiatriya, psikhosomatika 2011; 1: 8-15.

7. Marklund N., Bakshi A., Castelbuono D., Conte V., McIntosh T. Evaluation of pharmacological treatment strategies in traumatic brain injury. Curr Pharm Des 2006; 12(13): 16451680, https://doi.org/10.2174/138161206776843340.

8. Maas A.I. Neuroprotective agents in traumatic brain injury. Expert Opin Investig Drugs 2001; 10(4): 753-767, https://doi.org/10.1517/13543784.10.4.753.
9. Faden A.I. Neuroprotection and traumatic brain injury: theoretical option or realistic proposition. Curr Opin Neurol 2002; 15(6): 707-712, https://doi.org/10.1097/00019052200212000-00008.

10. Shokin M.N., Vlasov A.P., Khovryakov A.V. Clinical laboratory effect of mexidol at craniocerebral injury. Vestnik novykh meditsinskikh tekhnologiy. Elektronnoe izdanie 2011; 1. URL: https://medtsu.tula.ru/VNMT/Bulletin/E2011-1/3529.pdf.

11. Golubev S.S., Khovryakov A.V. The change of biochemical hypoxic indices in cerebrospinal fluid in traumatic brain injury in survived patients against the background of standard therapy and against the background of therapy with Citicoline and Mexidol. Molodoy uchenyy 2013; 6: 755-757.

12. Sernov L.N., Smirnov L.D., Shaposhnikova G.I., Guranova N.N. Clinical experimental study of anti-ischemic and hypolipidemic activity of Mexicor. Klinicheskie issledovaniya lekarstvennykh sredstv $v$ Rossii 2004; 1: 24-28.

13. Aaslid R., Markwalder T.-M., Nornes H. Noninvasive transcranial Doppler ultrasound recording of flow velocity in basal cerebral arteries. J Neurosurg 1982; 57(6): 769-774, https://doi.org/10.3171/jns.1982.57.6.0769.

14. Gaydar B.V., Semernya V.M., Vaynshteyn G.B. Concerning the interaction of blood flow level and reactivity of cerebral vessels with functional condition of cerebral tissue. Fiziologicheskiy zhurnal SSSR im. I.M. Sechenova 1986; 72(5): 603-611.

15. Gubler E.V., Genkin A.A. Primenenie neparametricheskikh kriteriev statistiki $v$ medikobiologicheskikh issledovaniyakh [The use of nonparametric statistic criteria in biomedical studies]. Leningrad: Meditsina; 1973; 144 p.

16. Lakina G.F. Biometriya [Biometrics]. Moscow: Vysshaya shkola; 1990; $352 \mathrm{p}$. 